\title{
Frontal and Naso-Orbito-Ethmoid Complex Fractures
}

\author{
Kannan Balaraman
}

\subsection{Introduction}

Naso-orbito-ethmoid (NOE) region is a confluence of critical structures of the face including the nose, orbit and skull base. Hence injuries to the region have a major impact on the function of these regions as well as aesthetics. A deformity of the NOE region tends to catch the eye much more than a deformity elsewhere in the face and hence affecting the individual. The injuries to this area are about $5 \%$ of maxillofacial injuries in adults and about $15 \%$ in children $[1,2]$ and mostly occur as a result of road traffic accidents (RTA) [1] especially in the Indian subcontinent. This is especially so due to two-wheeler injuries. Considering the proximity of the region to the brain and globe, these injuries may need multidisciplinary evaluation before embarking on a definitive treatment plan.

\subsection{Applied Surgical Anatomy}

The NOE complex is a part of the medial vertical buttress system of the face abutting the cranium. It is made of the nasal bones, the ethmoid bones encompassing the sinuses which also form the medial wall of the orbit articulating above with the frontal bone at the anterior skull base. This ethmoid labyrinth which separates both the orbits acts like a shock absorber during trauma thus minimizing force dissipation into critical structures like the orbital and cranial cavities. Extensive injury or comminution can result in associated anterior cranial base fractures causing cerebrospinal fluid (CSF) leak as well. The frontal process of maxilla and the lacrimal bone also is an integral part of the complex owing to their proximity and involvement in the fracture pattern occurring in the region.

\section{K. Balaraman $(\bowtie)$}

Department of Oral and Maxillofacial Surgery, Ganga Medical

Centre and Hospitals, Coimbatore, Tamil Nadu, India

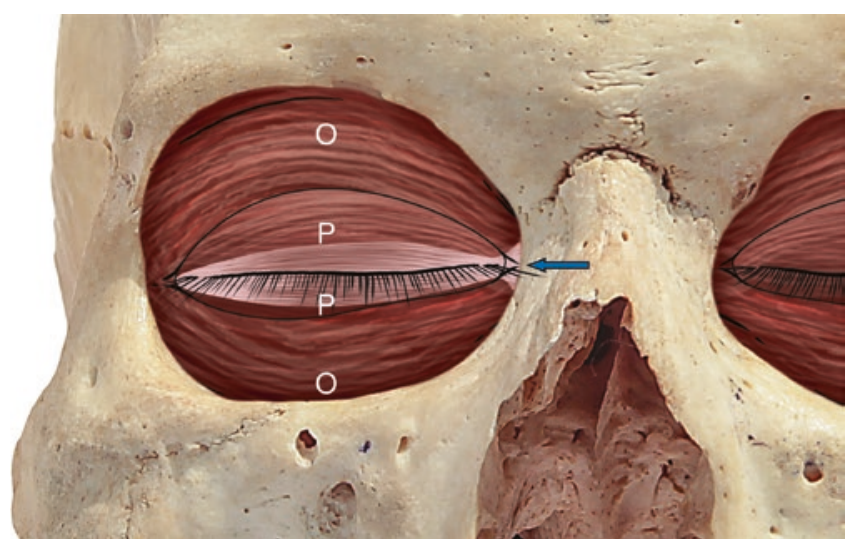

(C)Association of Oral and Maxillofacial Surgeons of India

Fig. 58.1 MCL anchoring eyelids (O-occular, P-palpebral)

Apart from the bony parts, the medial canthal ligament (MCL) is an important soft tissue of the complex (Fig. 58.1). The ligament not only anchors the upper and lower eyelids to the nasal complex but also encompasses the lacrimal sac at its anterior, posterior and superior aspect [3]. Certain authors have found that the posterior limb is not always present or clearly defined in certain instances [4]. The ligament being attached to the edges of the lacrimal fossa in the lacrimal bone in these areas helps in emptying of the lacrimal sac during blinking thus effecting drainage of the lacrimal sac. Hence injuries to the region affecting the attachment of the medial canthal ligament can impact the medial eyelid attachment and/or draining off tears from lacrimal sac. The skin and soft tissues drape over the complex like a cloth over a framework, and when the region crumples following an injury, the soft tissue envelope collapses as well causing distinct deformity which if not treated well can result in persistent deformity of the region. The collapsed soft tissue heals/ scars over the deformed bony complex and secondary correction at a later date do not help achieve the pre-injury status. Hence optimal primary realignment and repair offer the best chance of achieving optimal results [5]. 


\subsection{Historical Perspective and Classification [6]}

The treatment of NOE complex injuries has evolved from the previous century. Though nasal bone fractures have been recognized for a long time, the fracture of ethmoids was highlighted by Dawson and Fordyce in 1953. Converse and Smith in 1963 identified the involvement of medial orbital wall and termed it as naso-orbital. Stranc was the first to in modern English literature to adopt the terminology naso-ethmoid. Epker recognized the present-day terminology of nasoorbito-ethmoid in 1973, whilst Gruss in 1985 preferred the term naso-ethmoid-orbital [6].

\subsubsection{Classification}

Rowe and Williams [7] in their classic text highlighted the complexity of the area and stressed the need for primary management. Their classification was quite simple, depending on side involved and association with other fractures.

- Unilateral or bilateral

- Isolated or associated with other facial fractures

Markowitz and Manson (1991) [8] identified the importance of canthal ligament, and their classification reflected the need for getting the position of the canthal ligament either by manipulating the fragment or anchoring the canthus directly. Their classification was as follows (Box 58.1):

\section{Box 58.1 Markowitz and Manson Classification}

Type I Simple fracture with canthal ligament attachment intact

Type II Comminuted fracture with intact canthal attachment in the large fragment (positioning this fragment helps in securing the canthus in the right place)

Type Gross comminution with the canthal attachment

III in a small fragment or detached canthus both necessitating canthopexy

\subsubsection{Paediatric NOE Fractures (Fig. 58.2) Classification: Burstein et al.'s [9]} (Box 58.2)

\section{Box 58.2 Paediatric NOE Fracture Classification}

Paediatric NOE fractures classification types are:

- Burstein type I fracture-localized to the upper NOE complex and frontal bone, medial to superior orbital foramen

- Burstein type II fracture-involves half of the superior orbital wall, although it does not involve the NOE

- Burstein type III fracture-is bilateral and involves the superior orbital walls, upper NOE and bilateral frontal bones
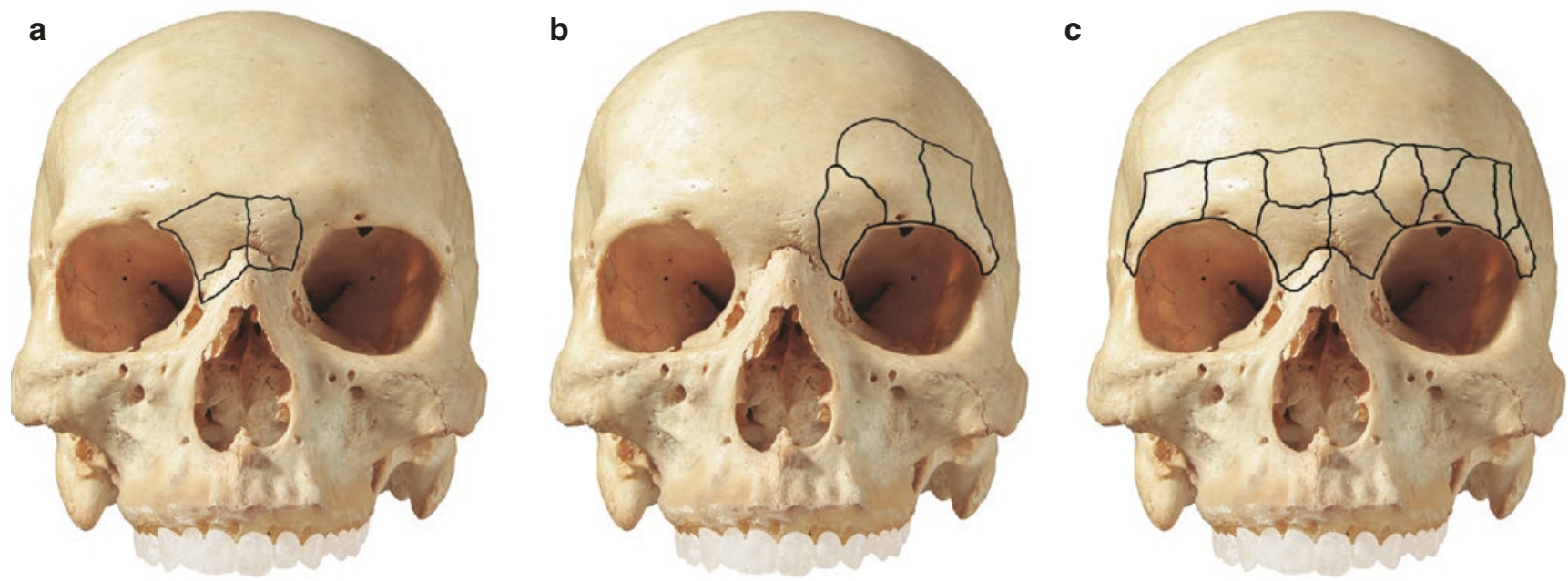

CAssociation of Oral and Maxillofacial Surgeons of India

Fig. 58.2 Paediatric NOE fractures classification 
Markowitz classification of adult NOE fractures does not take into account the differences in paediatric population such as:

- Midface-skull proportions

- Frontal sinus pneumatization

\subsection{Aetiology, Clinical Features and Diagnosis}

The most common aetiology of the fracture of NOE complex is trauma be it road accidents in unprotected individuals, assaults or fall from height [10].

Initial presentation can be disconcerting for the individual and bystanders due to profuse nasal bleeding and gross oedema around the midfacial skeleton. The signs and symptoms are given in Box 58.3 (symptoms) and Box 58.4 (signs).

\section{Box 58.3 Symptoms of NOE Fracture}

Periorbital swelling

Pain and discomfort

Epistaxis

Nasal blockade

- Widening of NOE area

\section{Box 58.4 Signs of NOE Fracture}

Nasal deformity with crepitus

Epistaxis_-blood or mixed with CSF

Depressed nasal bridge

Upturned nasal tip

Rounded medial canthus

Altered palpebral fissure shape

Blockage of nasolacrimal duct

- Accentuation of the nasojugal skin fold

- Formation of obtuse angle at the base of columela with tension on upper lip

- Lip separation caused due to ruptured tip of nose

Telecanthus

(a) lose of almond shape of palpebral fissure

(b) Transverse shortening of the palpebral aperture

(c) Eyelids become lax

(d) Epicanthal fold become more prominent

(e) Flattening of the bottom of naso-orbital valley

(f) Obliteration of the caruncle

(g) Diminished tension of canthal ligament
From the point of view of the examining clinician, Advanced Trauma Life Support (ATLS) protocols take precedence however gross the presenting scenario is (Refer Chap. 48 of this book). Once primary survey is completed and the patient cleared for secondary survey, definitive clinical examination starts. It is also imperative to rule out underlying injuries to the head/brain, ophthalmologic or associated structures prior to comprehensive maxillofacial assessment.

The main indicators suggesting an underlying NOE fractures include:

- Depressed nasal bridge (with or without upturned nasal tip) is a result of the loss of bony morphology (Fig. 58.3a, b). When the medial canthal ligament attachment is lost, the manifestations include loss of contour of palpebral fissure with rounded medial canthal region. The almond shape of the palpebral fissure is lost and becomes larger, and Bowstring test becomes positive (Fig. 58.4).

- Traumatic telecanthus is a direct indicator of the MCL disruption or widening of the fragments. When there is an intercanthal distance of $35 \mathrm{~mm}$ or more, then it may be an indication of the fragment with MCL being displaced. Direct physical examination is useful in identifying the collapsed complex.

\section{Measurement of Intercanthal Distance (ICD):}

Normal values are $32-33 \mathrm{~mm}$ for females and $33-34 \mathrm{~mm}$ for males. The rule of thirds can be applied whilst evaluating NOE fractures. Normally ICD equals the palpebral fissure width. However, in NOE fractures, increased ICD is found, called telecanthus (Fig. 58.5).

Telecanthus deformity is characteristic; the lateral displacement of MCT leads to rounding of the medial palpebral fissure, widening of the NOE region and transverse shortening of the palpebral aperture.

- Care should be taken to rule out CSF leak and also damage to the nasolacrimal duct. However the latter is difficult to assess primarily in some of the cases and may become apparent much later. Clear discharge from the nose or watery bloody discharge should arouse a high index of suspicion necessitating further biochemical investigations to differentiate CSF from nasal discharge. Glucose content is more in CSF, but assessment of Tau protein (beta 2 Transferrin) is the confirmatory diagnostic factor. Thorough neurologic and ophthalmologic assessment is also essential. In the acute setting, clinical examination is challenging due to the discomfort and 

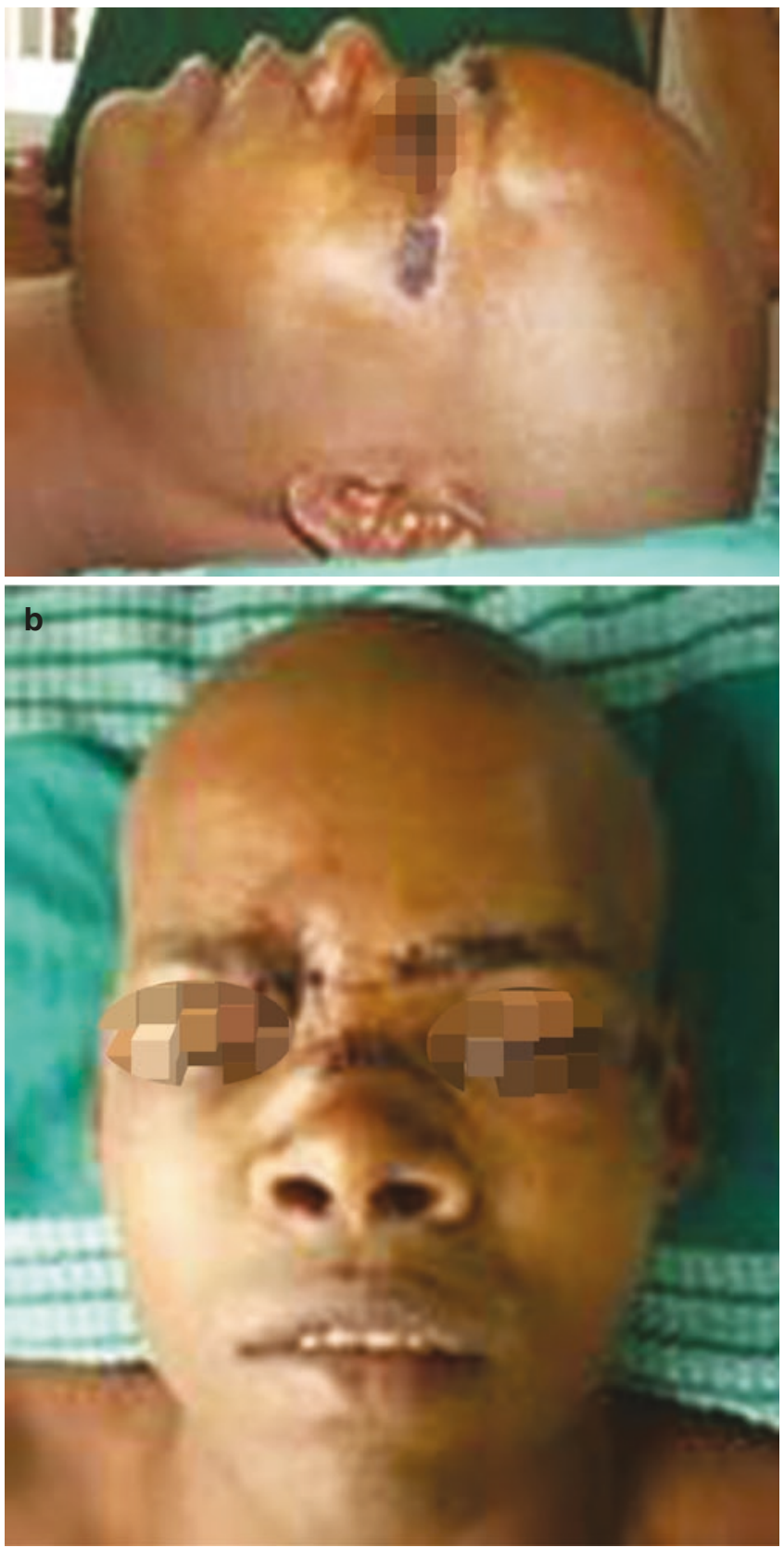

CAssociation of Oral and Maxillofacial Surgeons of India

Fig. 58.3 (a, b) Depressed, widened nasal complex with upturned tip of the nose

always may be inadequate [11, 12], and hence radiological investigations are mandatory. The diagnosis and understanding of the fractures has evolved over the last century with the advent of CT imaging. CT scan imaging in all planes is the norm in these fractures and helps in ruling injuries to the adjacent structures as well as assess-

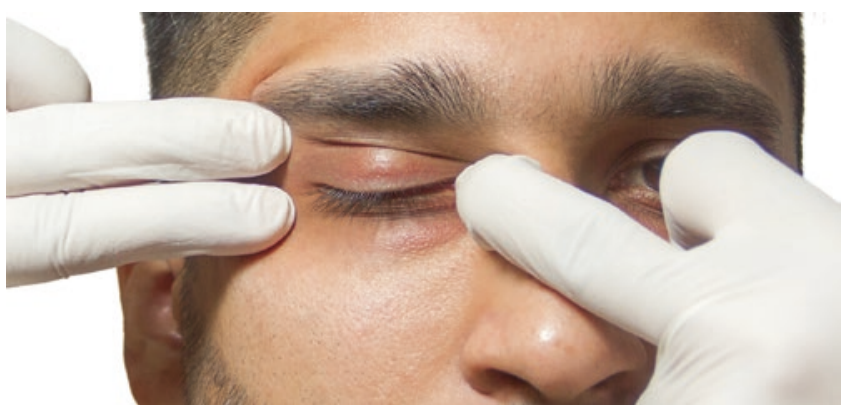

CAssociation of Oral and Maxillofacial Surgeons of India

Fig. 58.4 Bowstring test for assessment of MCL attachment patency

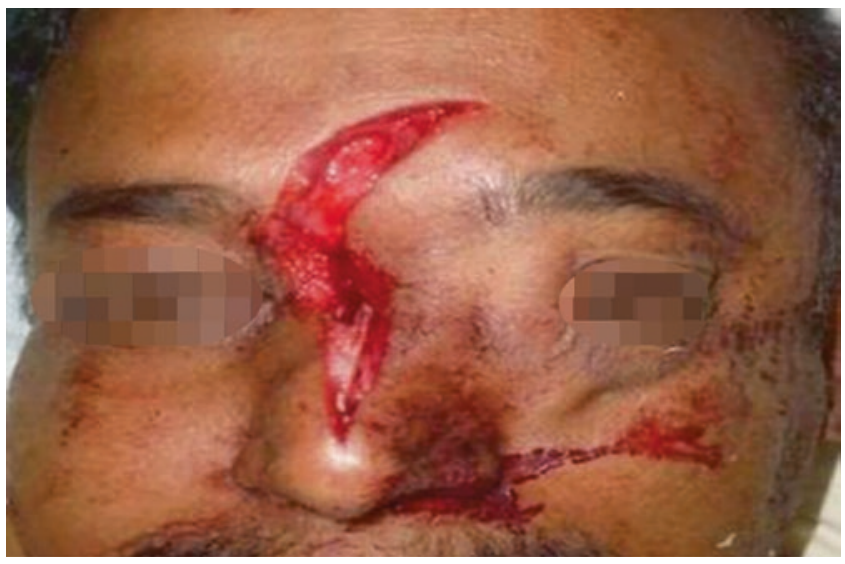

CAssociation of Oral and Maxillofacial Surgeons of India

Fig. 58.5 Traumatic telecanthus

ing the extent and nature of displacement of NOE complex injuries.

- High-resolution CT scan images in all planes (axial, coronal (Fig. 58.6a-d)) help to identify and assess the fracture pattern accurately. Thin sections $(0.6 \mathrm{~mm})$ not only help in better evaluation but also facilitate surgical planning or fabrication of models if required. The CT scans will be mandatory anyway to assess the head injury status in such cases, and these images can be a part of the head injury screening imaging. Communicating with the radiology department of the importance of such images will ensure that the required sections being done at the same instance of head injury assessment scans thus avoiding repeat scans. The axial sections show if there is disruption of the nasal complex or there is splaying of the ethmoid complex. The coronal sections depicts the displacement in the mediolateral aspect (thus the status of the fragment with the MCL), whilst the sagittal sections 

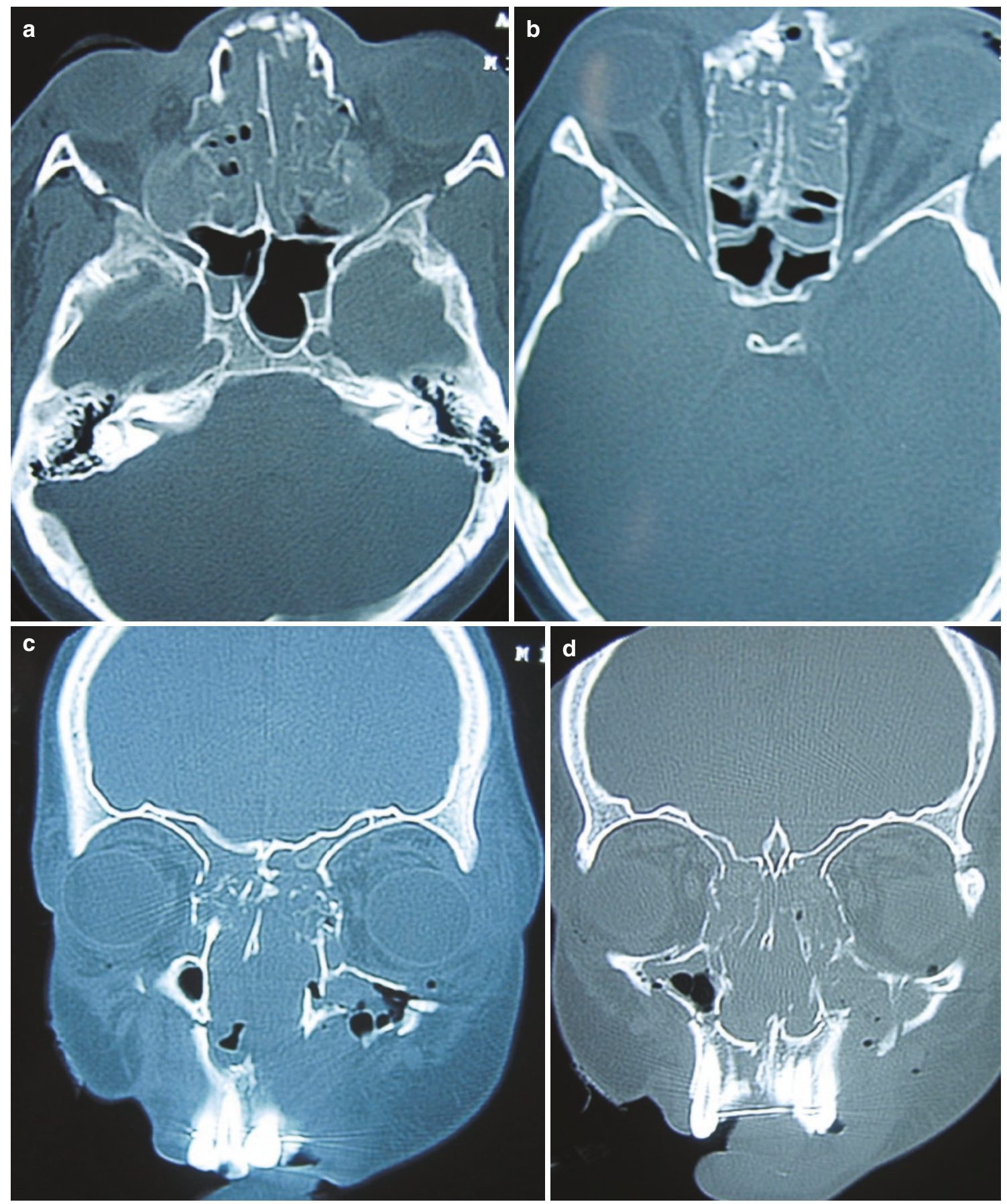

(C)Association of Oral and Maxillofacial Surgeons of India

Fig. 58.6 (a-d) Axial and coronal CT scan images of NOE fracture

depict the displacement in the anteroposterior (AP) aspect (depression).

- 3D reconstructed images show the gross morphologic status and are as accurate as the thinness of the sections.
Such images are good to plan the surgical management, discuss with the assistants the treatment goals and also explain to the patient the nature of the injury and proposed treatment plan as part of informed consent. 


\section{Test to Assess Integrity of MCT}

NOE fracture is positive if mobility of the medial canthal tendon is appreciated.

It is revealed by a Bowstring or a bimanual test.

- Bowstring Test:

When the eyelid is pulled laterally, a lack of resistance or detection of movement of the underlying bone at the tendon area is indicative of a fracture.

- Bimanual Test:

An instrument is placed in the nose and pushed laterally. Instability and crepitation felt at the tendon area suggests NOE fracture.

\subsection{Management}

The initial presentation of such patients occasionally may be dramatic due to profuse epistaxis which may exacerbate in someone lying down. Keeping patients sitting up with packs in the anterior nostril might help reduce the bleed. Persistent profuse bleed may necessitate intubation to secure the airway and packs in both anterior and posterior nasal passages to help prevent aspiration.

The patient once stabilized, and fit to undergo surgery will need a discussion with the anaesthesiologist about options of intubation. Fractures not involving occlusion can be managed by oral intubation, whilst if involving occlusion then options like submental intubation or even tracheostomy of the patient requires prolonged ventilation or due to have further surgical procedures (as in poly trauma patients).

The presence of CSF leak might pose a tricky problem. Instances of CSF leak are higher whenever there is pneumocephalus. Hence in such instances, an approach combined with neurosurgical team may be mandatory, whilst involvement of an ophthalmologist is mandatory when there is involvement of lacrimal drainage system or lid adnexa. The treatment goals of NOE are shown in Box 58.5.

\section{Box 58.5 Treatment Goals of NOE Fracture}

Treatment goals

Restoring the nasal projection

Restoring nasal dorsal height with adequate nasofrontal angle

Re-establishing the MCL attachment

Restoring the latency of nasolacrimal duct
Conventionally the nasal complex was treated with closed reduction till Adam et al. [6] reported on the importance of nasal wiring. The importance of involving the medial canthal region in the treatment plan was initiated by Converse and Smith in 1963 [6]. They emphasized the importance of manipulating the segment with the MCL, forward positioning the fragment and trans nasal wiring over a perforated plate.

The case for open reduction and internal fixation (ORIF) was highlighted by Dingman and Natvig [13]. They reported superior results have been achieved in the more serious injuries (with minimum of effort and with the greatest degree of comfort to the patient) by open reduction with direct fixation. The need and feasibility of identifying MCL and anchoring it across to the other side was described by Mustarde in 1964 [14]. The need for primarily bone grafting when there is severe comminution of the nasal dorsum rendering primary reduction incomplete and also help achieve single-stage reconstruction was highlighted by Cruse [15] and Gruss [16].

Reduction of the nasal complex may be done with Walsham's forceps to realign the deviated/displaced complex. The collapsed complex may be out-fractured, and complex opened out may need to be in-fractured. The depressed complex may be elevated into position by the septal forceps (Ash's). However in displaced or comminuted scenarios, closed reduction isn't optimal. Hence trans nasal wiring may be needed to keep the splayed segments well reduced and minimize telecanthus. In the absence of gross comminution, closed reduction and trans nasal wiring has been proved quite useful and adequate to achieve optimal results as advocated by some authors especially in patients with associated maxillary fractures [17].

\subsubsection{Surgical Access for NOE}

1. Existing laceration (Fig. 58.7)

2. Glabella approach-a horizontal skin incision over the glabella region (Fig. 58.8)

3. Bicoronal approach (Fig. 58.9)

4. Butterfly incision (combination of Gullwing and open sky incision) (Fig. 58.10)

5. Vertical incision (Fig. 58.11)

6. H-shaped incision (Fig. 58.12)

Ed Ellis et al. [11] reported on having a sequential plan to proceed with the surgical sequence. They emphasized on adequate exposure for identification of the bone fragment with the MCL tendon, realigning the medial rim and canthopexy if required. The nasal dorsum reconstruction is planned at the end. 


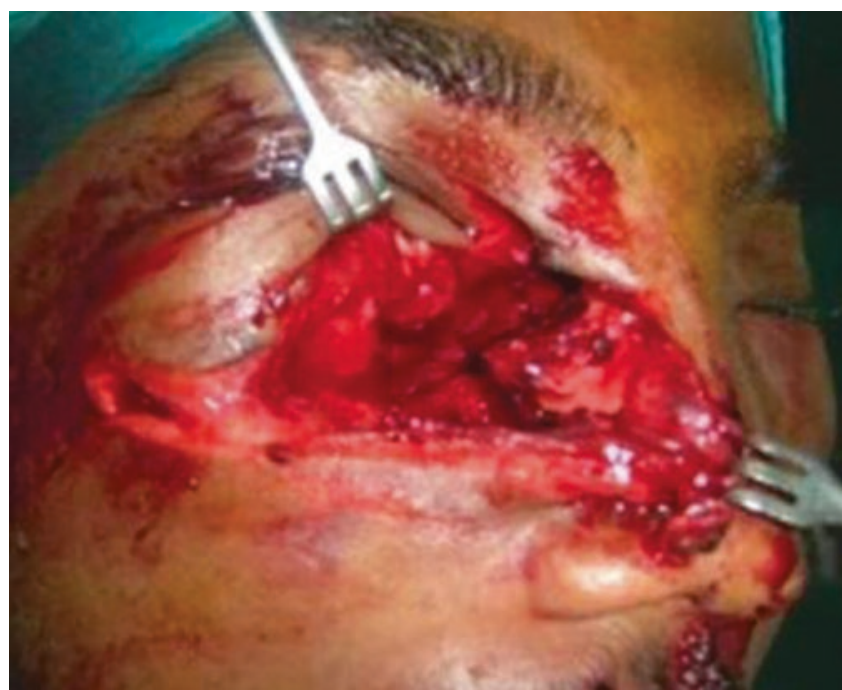

CAssociation of Oral and Maxillofacial Surgeons of India

Fig. 58.7 Existing laceration used as an approach

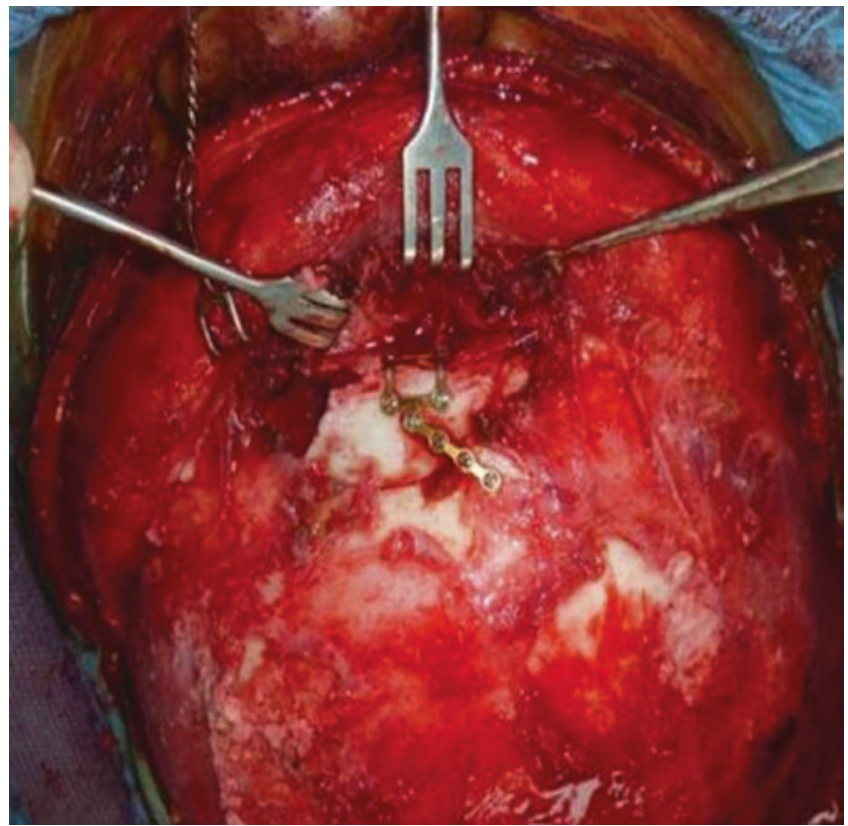

CAssociation of Oral and Maxillofacial Surgeons of India

Fig. 58.9 Bicoronal approach

According to them pre-treatment photographs are very important in getting good results, and deformity should be overtreated than undertreated because secondary deformity which occurs is difficult to treat.

\section{Trans nasal wiring:}

Closed reduction in established fractures with telecanthus rarely helps achieve adequate reduction and MCL reposi-

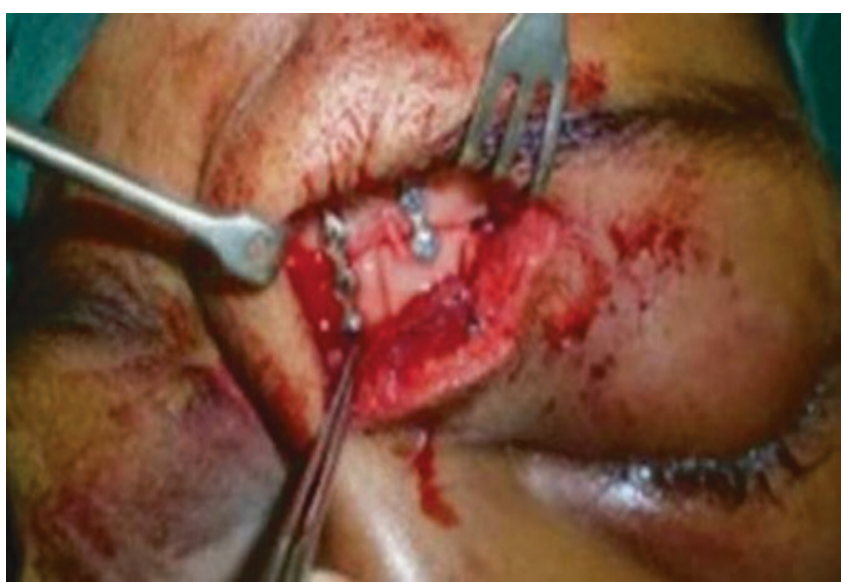

CAssociation of Oral and Maxillofacial Surgeons of India

Fig. 58.8 Glabella approach

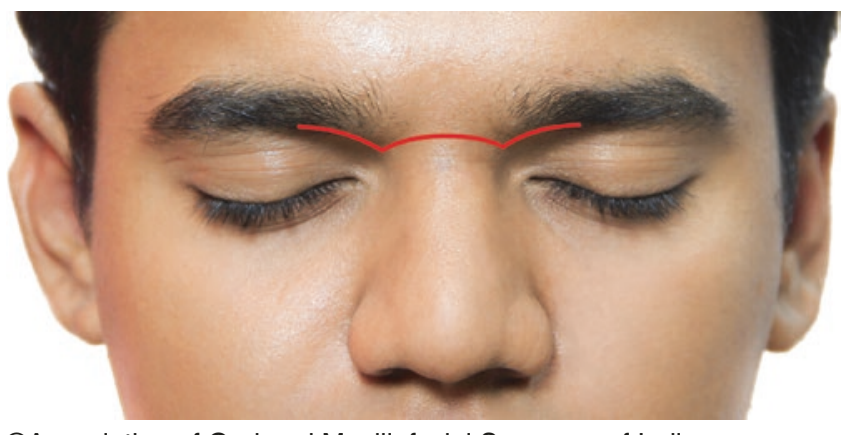

CAssociation of Oral and Maxillofacial Surgeons of India

Fig. 58.10 Butterfly incision (combination of Gullwing and open sky incision)

\section{Steps in Management}

- Step1: Good exposure

- Step 2: Identify the medial canthal tendon/tendonbearing bone

- Step 3: Reduce and reconstruct medial orbital rim

- Step 4: Reconstruction of medial orbital wall

- Step 5: Trans nasal canthopexy

- Step 6: Reduce septal fracture/displacement

- Step 7: Nasal dorsum reconstruction/augmentation with bone graft

- Step 8: Soft tissue readaptation (nasal splint, trans nasal bolsters, silicone sheeting)

tioning and hence may need trans nasal wiring as well to help with MCL positioning [6, 13]. Using a $\mathrm{K}$ wire driver or an awl will help pass a trans nasal wire across the nasal complex and help narrow the area by bringing the sides together. To help achieve adequate narrowing and restore 


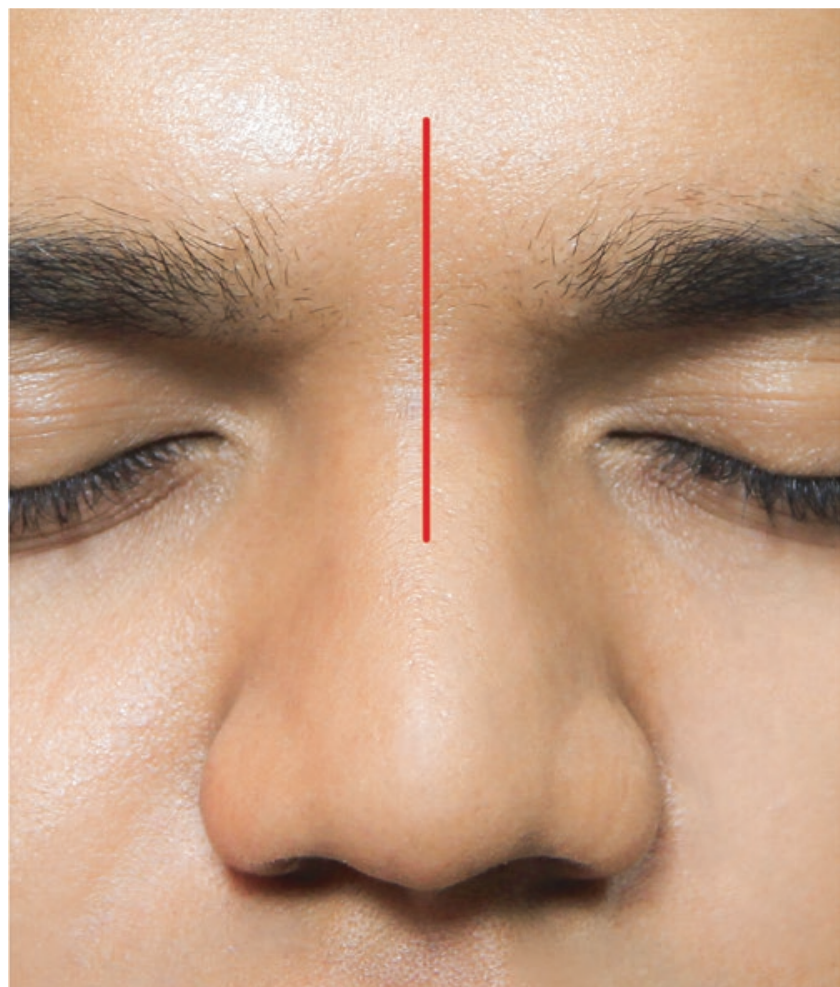

CAssociation of Oral and Maxillofacial Surgeons of India

Fig 58.11 Vertical incision

the canthal distance, the entry area on the affected site should be just superior and posterior to the posterior lacrimal crest to which the posterior limb of the ligament is attached. The wire entry point anterior to the area can result in widening of the telecanthus as the posterior aspect flares laterally.

As long as a large fragment with MCL attachment is identifiable, open reduction and fixation of the fragment can help in achieving our objectives. Using very low profile titanium plates (1.1-1.3 mm depending on the system used) helps achieve adequate fixation. Rigid fixation needs exposure of a stable area to help achieve the same and may necessitate exposing the glabella or frontal bone superior to it for adequate results. Realignment of the fragments and fixation will help in achieving better results in cases of fracture having multiple fragments and reconstruction with bone graft wherever required (Fig. $58.13 \mathrm{a}, \mathrm{b}$ ).

MCL disruption or a tiny bony fragment with MCL might necessitate a canthopexy.

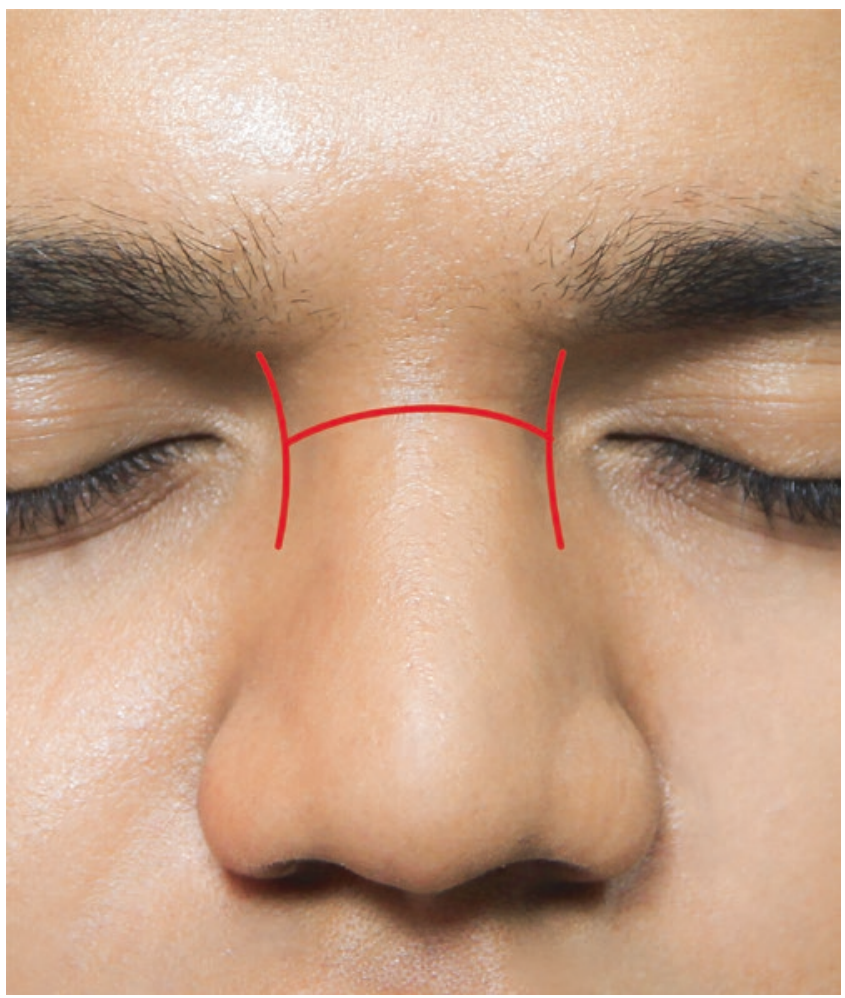

(CAssociation of Oral and Maxillofacial Surgeons of India

Fig. 58.12 H shaped incision

\subsubsection{Trans Nasal Canthopexy}

The objectives of trans nasal canthopexy are:

- To medialize the central fragment

- To position the tendon posterior and superior to posterior lacrimal crest that would give an ideal vector.

The commonly used methods are the trans nasal wiring (Fig. 58.14) or using a canthal barb. The identified ligament edges are either anchored with a suture (size 2-0 prolene) or a wire (26 gauge) and guided to the opposite side. The entry point is posterior and superior to lacrimal crest to ensure adequate positioning. One way to help achieve this is to adapt a plate in medial aspect extending from lateral nose onto the medial wall extending just beyond the lacrimal crest (Fig. 58.15).

The wire or suture anchoring the MCL is passed through a hole of the plate just beyond the lacrimal crest brought to 

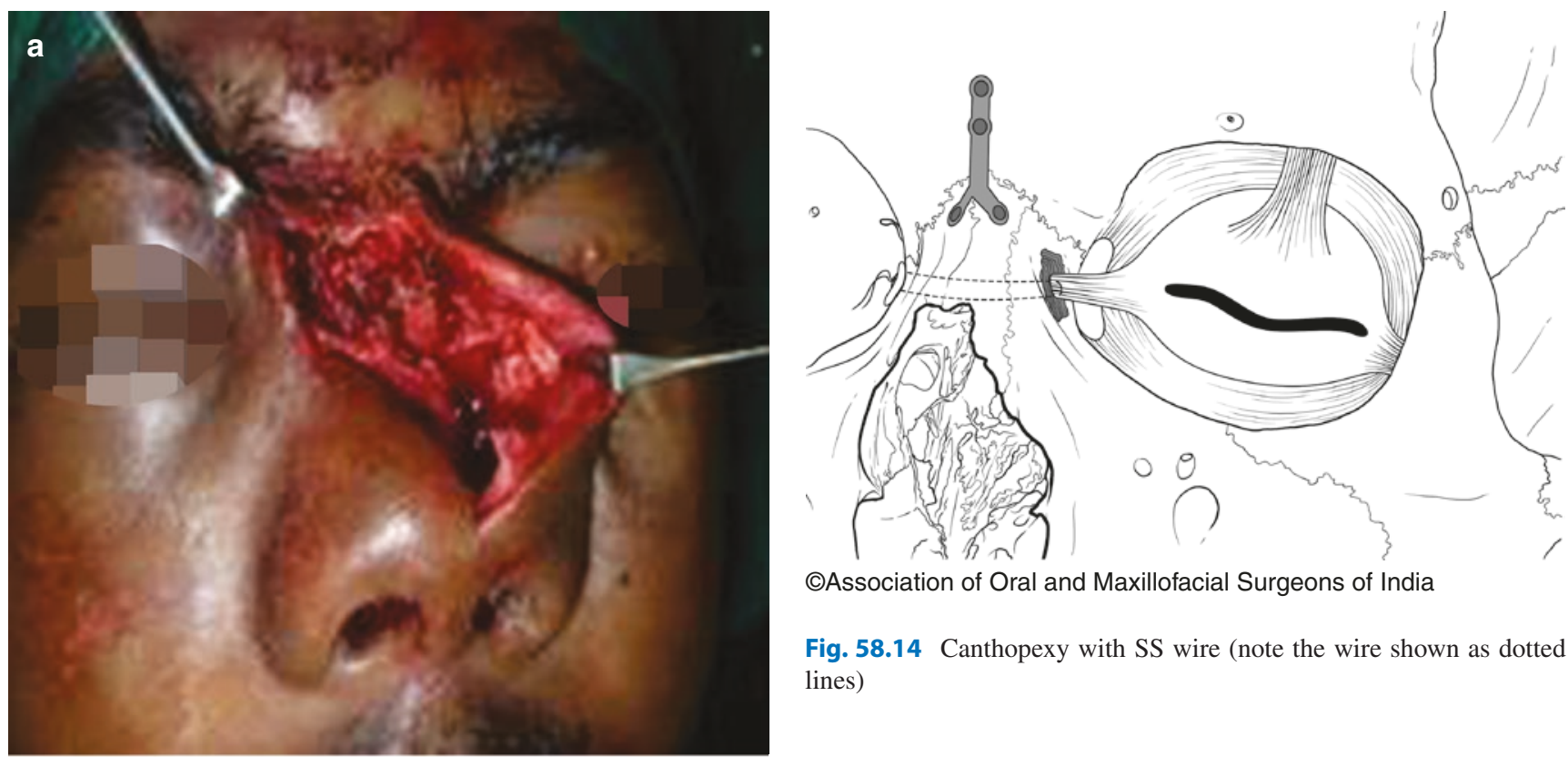

CAssociation of Oral and Maxillofacial Surgeons of India

Fig. 58.14 Canthopexy with SS wire (note the wire shown as dotted lines)

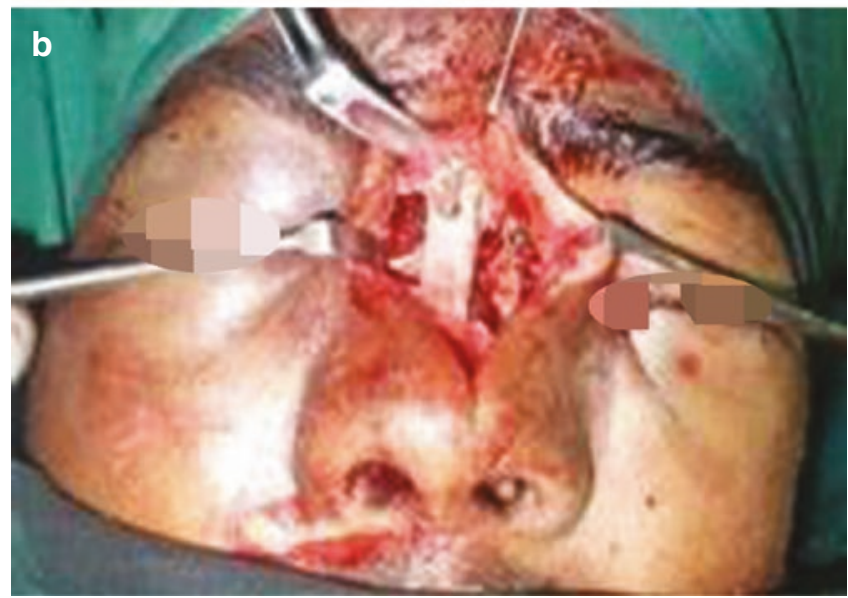

CAssociation of Oral and Maxillofacial Surgeons of India

Fig. $\mathbf{5 8 . 1 3}$ (a) Alignment and fixation of stable fragments. (b) Bone grafting of the dorsum of nose

the opposite side and secured around a screw in the forehead adjacent to the midline or a plate to prevent the wire cutting through the bone. Special barbed wires have been advocated by certain authors to engage the MCL and anchor it to help with medial canthopexy with small incisions around the medial canthus. These help especially when there is medial canthal disruption without bony disruption $[18,19]$.

Figure 58.16 shows a clinical case where the MCL has be anchored to the holes of the plate on either sides (arrows) with SS wires.

Paediatric injuries of the naso-maxillary complex are generally under treated, but they need similar management protocols like that of an adult to achieve optimal results [20]. The use of resorbable implants will be of prudence in the paediatric patients [3].

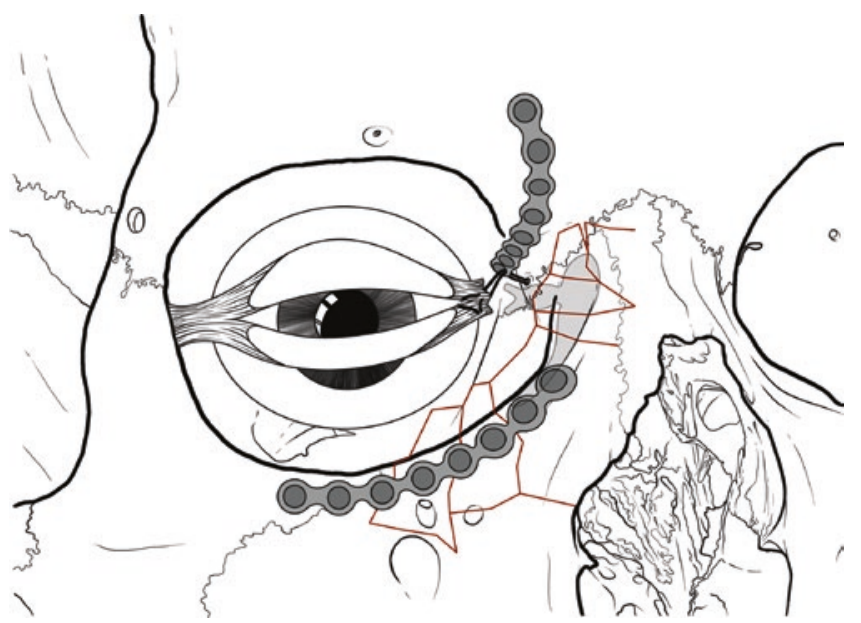

CAssociation of Oral and Maxillofacial Surgeons of India

Fig. 58.15 Use of plate to guide MCL reattachment (note the MCL fixed to plate with a wire, the red lines denote the fractured bones)

Post-operative aesthetic assessments of outcomes done for the management options comparing the canthal position and nasofrontal angle measurements have indicated that bone grafting may result in obtunded nasofrontal angle as compared to ORIF. Closed reduction of the complex has resulted in under projection of the nasal bridge region [20].

\subsubsection{Soft Tissue Readaptation} ORIF or NOE fractures. It plays the following functions:

- It reduces post-operative swelling due to oedema and haematoma.
A post-operative nasal bolster splint is very important after 


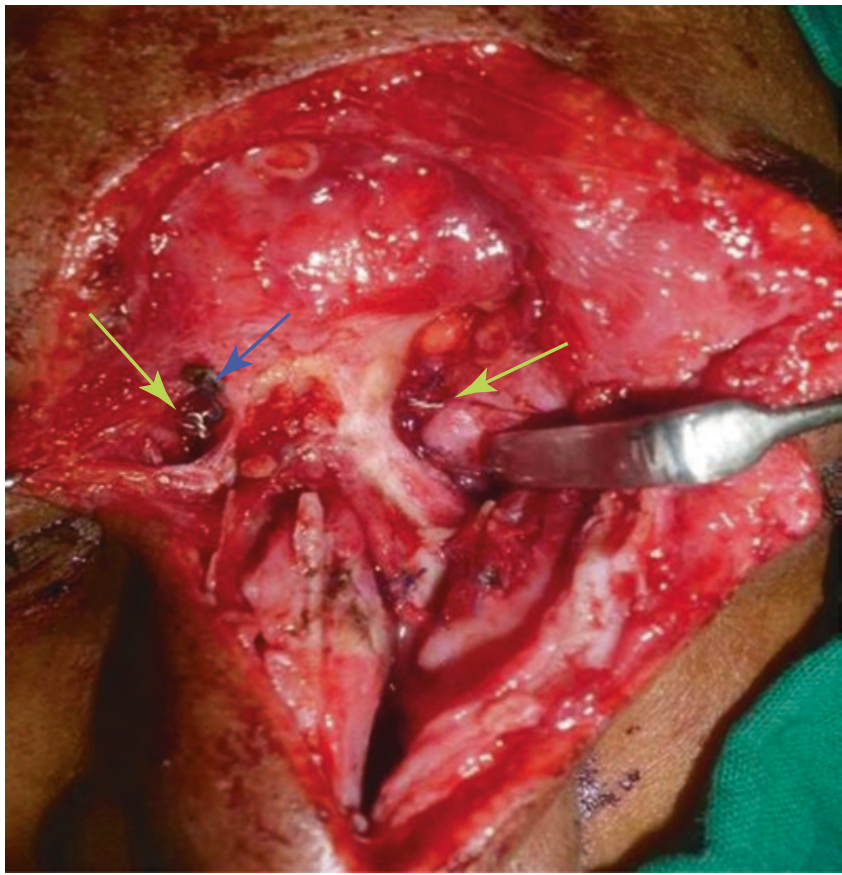

CAssociation of Oral and Maxillofacial Surgeons of India

Fig. 58.16 shows a clinical case where the MCL has been anchored to the holes of the plate (blue arrow) on either sides with SS wires (yellow arrow)

Redrapes soft tissues to underlying skeletal framework and prevents pseudo telecanthus (increase in intercanthal distance, in spite of accurate reduction and fixation of facture fragments. This occurs due to non-adaptation of soft tissues to the underlying NOE complex, with resultant fibrosis of tissues). Bolster splints may cause skin necrosis if used inappropriately. After reduction and fixation of NOE, nasal packing has been done with ribbon gauge soaked in paraffin/ flavine emulsion or bismuth iodoform paraffin paste (BIPP). Over packing should be avoided. Sometimes it obstructs the airway and a potential source of infection and required removal after $72 \mathrm{~h}$ postsurgery.

\subsubsection{Post-operative Evaluation [20]}

It includes evaluation of:

- Nasofrontal angle

- Nasal prominence and

- Intercanthal width

The average distance between the medial canthus should be approximately $1 / 3 \mathrm{rd}(33 \%)$ of the distance between lateral canthus. The distance from the lateral canthus of the eye to cornea and cornea to nasofrontal junction will be compared, and they should be in 1:1 relationship. The ideal naso-orbital angle is approximately $115-130^{\circ}$. All the three parameters

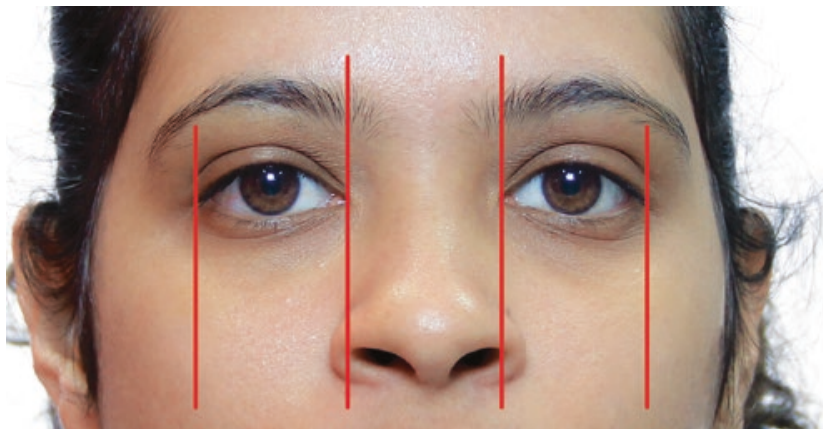

CAssociation of Oral and Maxillofacial Surgeons of India

Fig. 58.17 Ideal intercanthal distance

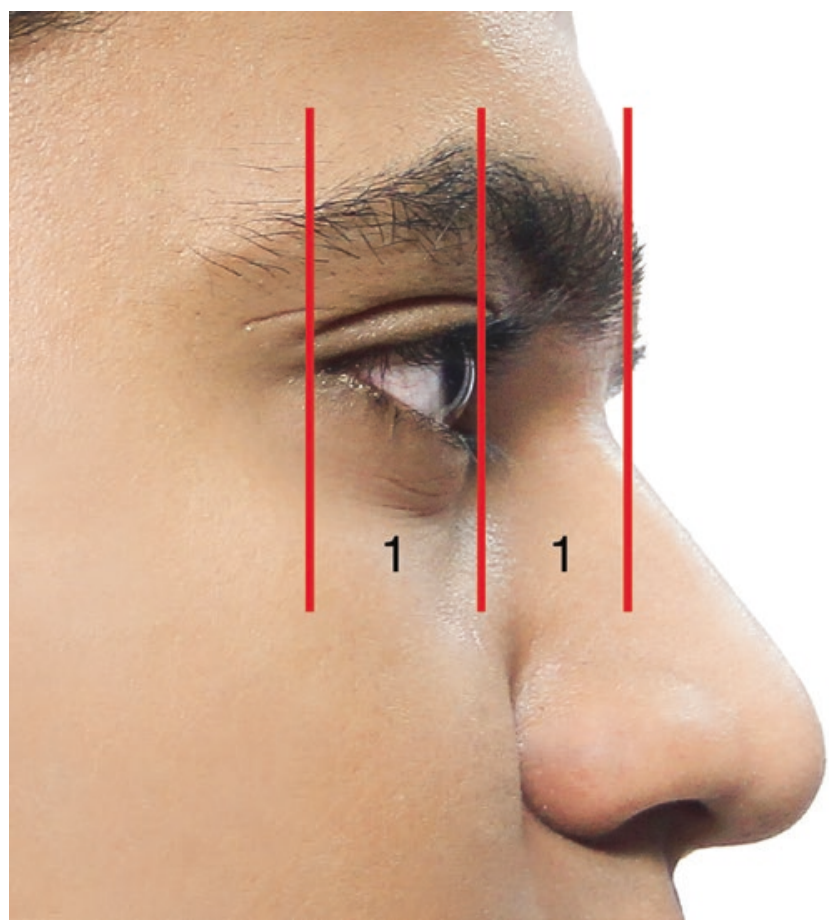

CAssociation of Oral and Maxillofacial Surgeons of India

Fig. 58.18 Ideal nasal projection (1:1)

should be checked post-operatively to assess the surgical results (Figs. 58.17, 58.18, and 58.19).

\subsection{Complications}

Inadequate assessment and treatment planning may result in incomplete management of the NOE complex resulting in secondary deformity which can aesthetically inadequate. Deformities of the NOE are quite easily noticeable compared to those in other regions, and hence appropriate management helps achieve good results. The aesthetic issues like persistent telecanthus or depressed nasal bridge are difficult to correct secondarily with suboptimal results. Hence the first time is the best time to address the central nasal component [21, 


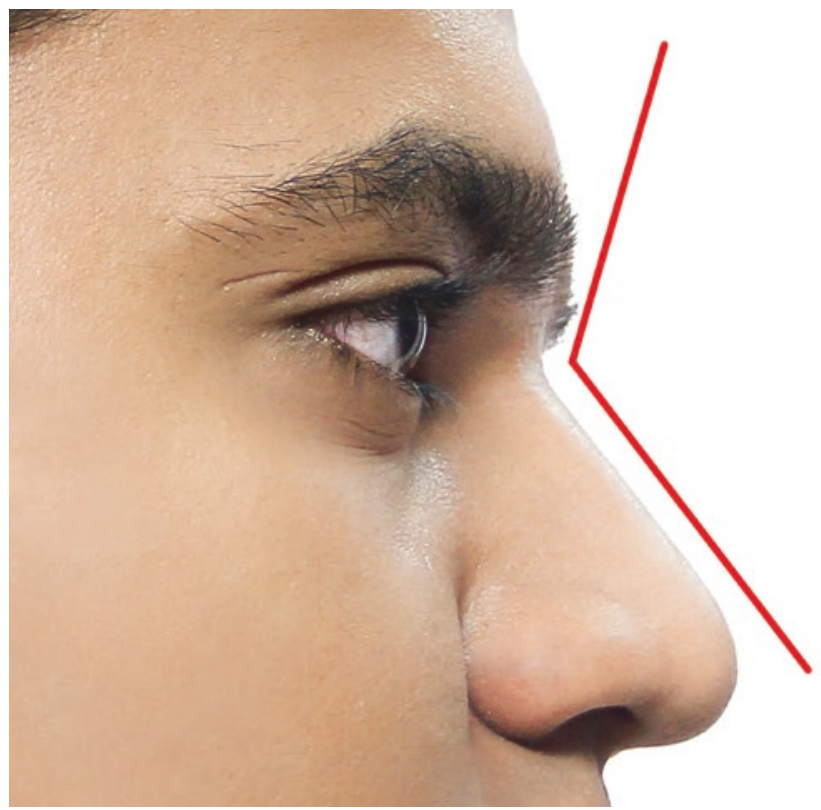

CAssociation of Oral and Maxillofacial Surgeons of India

Fig. 58.19 Ideal frontonasal angle

22]. Apart from aesthetic complications, functional issues like epiphora due to nasolacrimal duct injury or obstruction may manifest which may need stenting [23] or dacryocystorhinostomy (creating a osteum in the lateral nasal wall adjacent to the lacrimal sac along with stenting) to establish patency. Involvement of the medial wall may result in diplopia [24] which if not addressed adequately may persist. Another important issue overlooked is anosmia, but if it should occur, recovery is unpredictable, and prior discussion with patients is better. In cases with concomitant brain injuries or CSF leak, risk of associated sequelae is present, and a multidisciplinary approach helps. Though improperly placed trans nasal wires may occlude/impede the lacrimal drainage apparatus, it remains a popular modality to help treat these fractures $[25,26]$.

\subsection{Frontal Sinus Fracture}

\subsubsection{Introduction}

Fractures of the frontal sinus are frequently associated with orbital, NOE, nasal and anterior cranial fossa injury. Frontal sinus is most frequently damaged as a result of high velocity motor vehicle accidents. $70 \%$ of frontal sinus fractures were due to automobile accidents and $20 \%$ due to assaults. Proximity of sinus to the brain makes untreated disease in this area potentially fatal. Inappropriate treatment of frontal sinus fracture can lead to mucocele formation, recurrent sinusitis, osteomyelitis of frontal bone, brain abscess or thrombosis of cavernous sinus, encephalitis, etc. [27].

\subsubsection{Applied Anatomy of Frontal Sinus}

Frontal sinuses are two asymmetric sinuses separated by a thin bony septal plate. The average dimensions of frontal sinus are as follows [28]:

- Height: $32 \mathrm{~mm}$

- Width: $26 \mathrm{~mm}$

- Depth: $17 \mathrm{~mm}$

- Surface Area: $720 \mathrm{~mm}^{2}$

The frontal sinus is an air-filled cavity lined by pseudostratified ciliated columnar epithelium encased in bone. It becomes visible radiographically at the age of 6 years. The posterior table is thinner than the anterior table. The posterior table separates the sinus from dura of frontal lobe. Anterior table is covered by a soft tissue layer of frontalis muscle, orbicularis oculi muscle, supraorbital and supratrochlear nerves, vessels and skin. Posteriorly, the floor of the frontal sinus consists of orbital plate of frontal bone. Anteriorly, the floor of the sinus overlies the anterior ethmoidal sinus and nasal cavity. The frontonasal drainage area of the sinus originates from the posteromedial part of sinus floor. The frontal sinus drains through the frontonasal ducts into the middle meatus of the nasal cavity or directly through the ostia into the nasal cavity.

\subsubsection{Functions of Frontal Sinus}

Following are the various functions of the frontal sinus:

1. Production and storage of mucus

2. Resonator for voice

3. Humidification and warming of inhaled air

4. Accessory area of olfaction

5. Conservation of heat from the nasal fossae

6. Definition of facial contours

7. "Surge Tank" to dampen the pressure differential that develops during inspiration

The diagnosis of the frontal sinus fracture based on the proper history and physical examination of the patient which includes inspection and palpation of the affected area.

The detailed history includes the following points:

1. Information about events

2. Visual difficulties

3. Numbness

4. Pain

5. Rhinorrhea

6. Sense of smell

7. Previous history of nasal or sinus disease surgery 


\subsubsection{Clinical Features [29]}

1. Forehead laceration (58\%)

2. Forehead pain (82\%)

3. Swelling

4. Frontal bone depression (25\%)

5. Periorbital ecchymosis

6. CSF rhinorrhea (1/3rd patients)

\subsubsection{Radiographic Features}

For an accurate diagnosis of frontal sinus fracture, a CT scan (Fig. 58.20a, b) in different views must be examined [30].

1. Axial view: It reveals location, severity and degree of comminution of anterior and posterior table fractures.
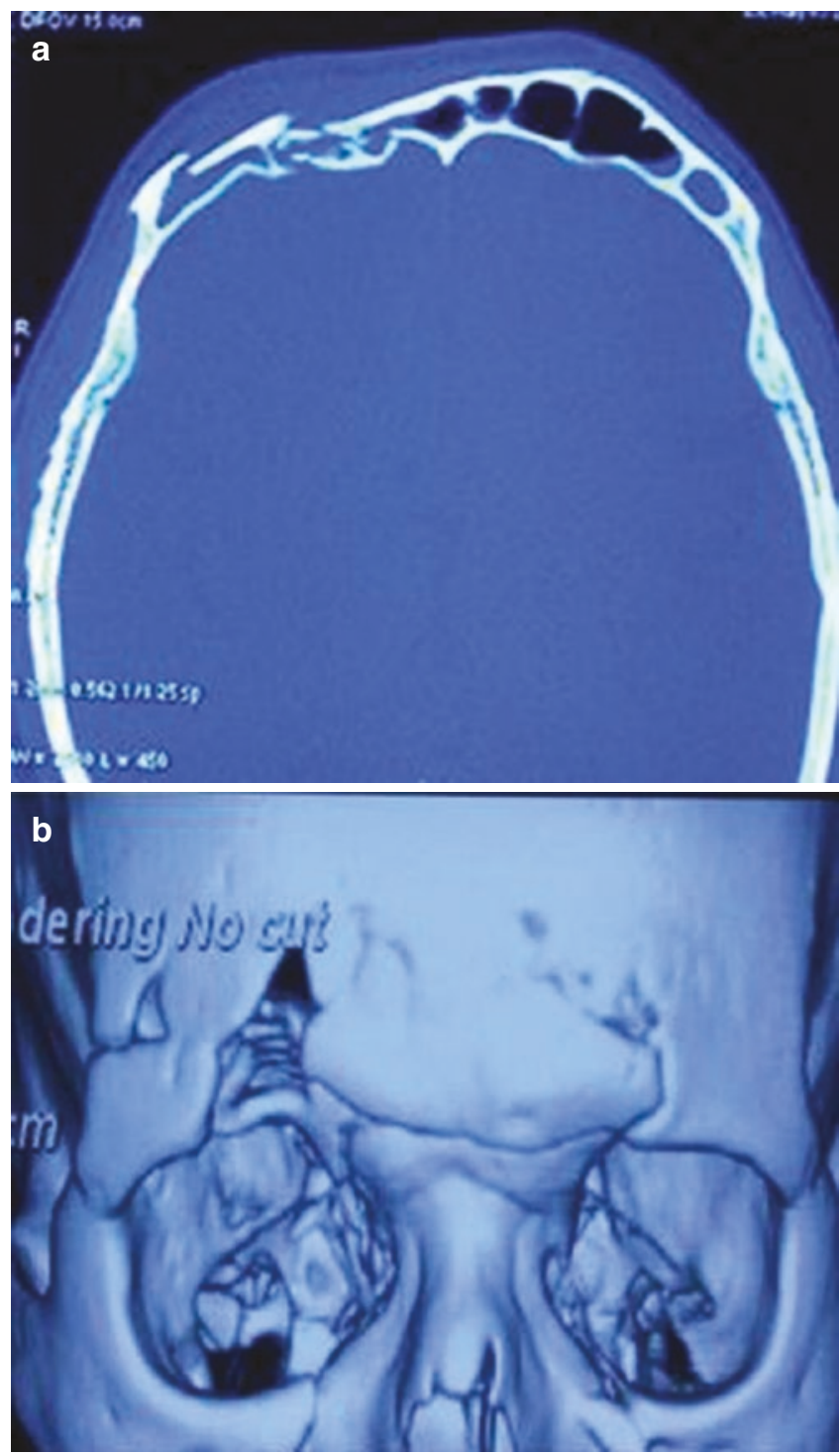

CAssociation of Oral and Maxillofacial Surgeons of India

Fig. 58.20 (a, b) 3D CT and axial CT image with frontal sinus fracture
2. Coronal view: It reveals frontal sinus floor and orbital roof fractures.

3. Sagittal view: It assesses frontonasal duct.

4. Submentovertex view and lateral view: It visualizes anterior and posterior tables.

\subsubsection{Classifications}

Frontal sinus fractures are usually classified based on:

- Location

- Extent of injury

- Involvement of frontonasal duct

- Current injury to the dura

\subsubsection{Stanley's Classification of Frontal Sinus Fracture [31]}

- Type I: Anterior Table Fracture

- Isolated to anterior table

- Accompanied by supraorbital rim fracture

- Accompanied by naso-ethmoid complex fracture

- Type II: Anterior and Posterior Table Fractures

- It is a linear fracture either on transverse direction or in vertical direction

- Type III: Comminuted Fractures

- Isolated to both tables

- Accompanied by naso-ethmoid complex fracture

\subsubsection{Gonty Et al. Classification of Frontal Sinus Fracture [32]}

- Type I: Anterior Table Fracture

- Isolated to anterior table

- Accompanied by supraorbital rim fracture

- Accompanied by naso-ethmoid complex fracture

- Type II: Anterior and Posterior Table Fractures

- A linear fracture either on transverse direction or in vertical direction

- Comminuted fracture either isolated to both tables or accompanied by naso-ethmoid complex fracture

- Type III: Posterior Table Fracture

- Type IV: Through and Through Frontal Sinus Fracture

\subsubsection{Management (Box 58.6) [33]}

\section{Surgical Access:}

1. Through existing laceration

2. Butterfly incision (Fig. 58.10)

3. Gullwing or eyeglass incision (Fig. 58.21) 
Box 58.6 Guiding Principles for Frontal Sinus

Management

- To separate nasal cavity from sinus

- To eliminate dead space

- To separate the frontonasal duct from frontal sinus by obstructing the duct

- To eliminate a functional sinus, sinus mucosa is removed, and sinus is obliterated

4. Bicoronal approach (Fig. 58.9): Khan et al. in 2018 [34] suggests sterile surgical glove tourniquet intraoperatively to get the haemorrhage control and blood less surgical field in elevation of bicoronal flap for the surgical management of frontal sinus fracture.

\subsubsection{Indications of Surgery in Frontal Sinus Fractures [35]}

1. To avoid immediate complications such as CSF leak, meningitis

2. To avoid long-term complications such as frontal sinusitis, meningitis and brain abscess formation

3. To provide aesthetic contour to the forehead

4. To provide exposure for anatomic reduction of NOE fractures

\subsubsection{Management of Anterior Table Fracture [36-38]}

\section{Decision-Making:}

- Simple greenstick or undisplaced fracture does not require surgical intervention.

- In depressed anterior wall fracture, frontal sinus explored, careful irrigation carried out, fragments reduced and stabilize by internal fixation. In posterior wall fracture without CSF leak or pneumoencephalus, reconstruction of only anterior wall is done.

Other than surgical intervention, antibiotics, sinus decongestants and analgesics are prescribed to keep the frontonasal duct patent and to prevent infection.

Rai et al. [39] suggested bone mapping/sketching in management of anterior table frontal sinus fracture with great success. To get good post-operative contour, each fracture fragment is to be placed at the original position after debridement of the sinus. For the same purpose, numbers have to be given to the fracture fragments on a plane paper (sterile glove covering paper) or green sheet (Fig. 58.22a-c).

Yoo $\mathrm{MH}$ et al. suggested endoscopic trans nasal reduction of anterior table fracture [40]. To support the reduced frag-

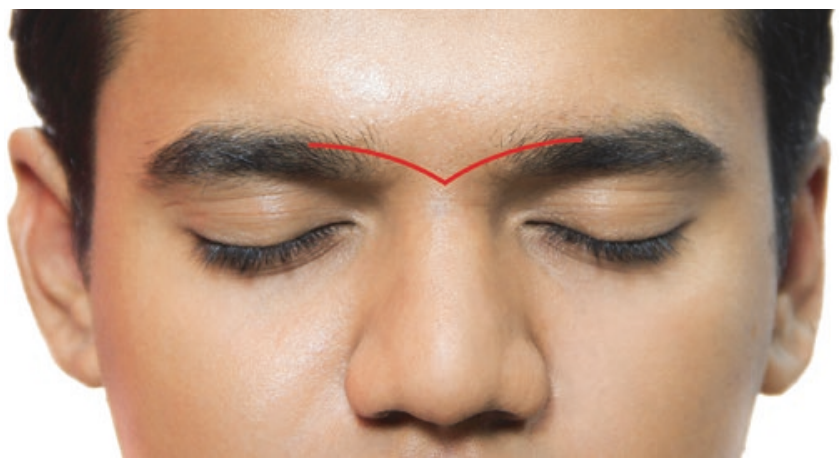

CAssociation of Oral and Maxillofacial Surgeons of India

Fig. 58.21 Gullwing or eyeglass incision

ments, they advocated use of custom made latex glove balloon to be inserted into the frontal sinus then expanded and maintained for 3 weeks. It avoid use of coronal incision is the advantage of endoscopic reduction. It should be avoided in severe comminuted fractures, displaced posterior table fracture with evidence of dura tear, associated orbital roof blow in fracture and extensive skull bone fractures.

\subsubsection{Treatment of Posterior Table Fracture} [41]

Patients with displaced and comminuted posterior wall combined with or without anterior wall require the support of a neurosurgeon because of dural and intracranial lesions. To get the good exposure, bifrontal craniotomy is indicated to eliminate the posterior wall.

To widen the neurosurgical access to the anterior floor of the cranium, the supraorbital bandeau will be temporarily removed. The sinus mucosa carefully removed with bur, and sinus is cranialized, and then repair of the dura will be carried out- Calvarial bone graft used to obliterate the nasofrontal duct and bone powder can be used to cover the remaining dead space. Anterior table can be stabilized with bone plates and screws. Bone defect will be treated with calvarial bone graft or titanium mesh. With patent duct and no concurrent dural tears or brain injury exist, any amount of posterior table displacement is inconsequential and managed by observation.

\subsubsection{Methods of Treatment of Damaged Frontonasal Duct [42]}

The damage to the nasofrontal duct and frontal sinus obstruction increases the risk of mucocele formation and inflammatory complications post-operatively. Obliteration of the duct is indicated in such situation. The muscle, temporalis fascia, bone chips, etc. are the materials used commonly to obstruct the duct. 

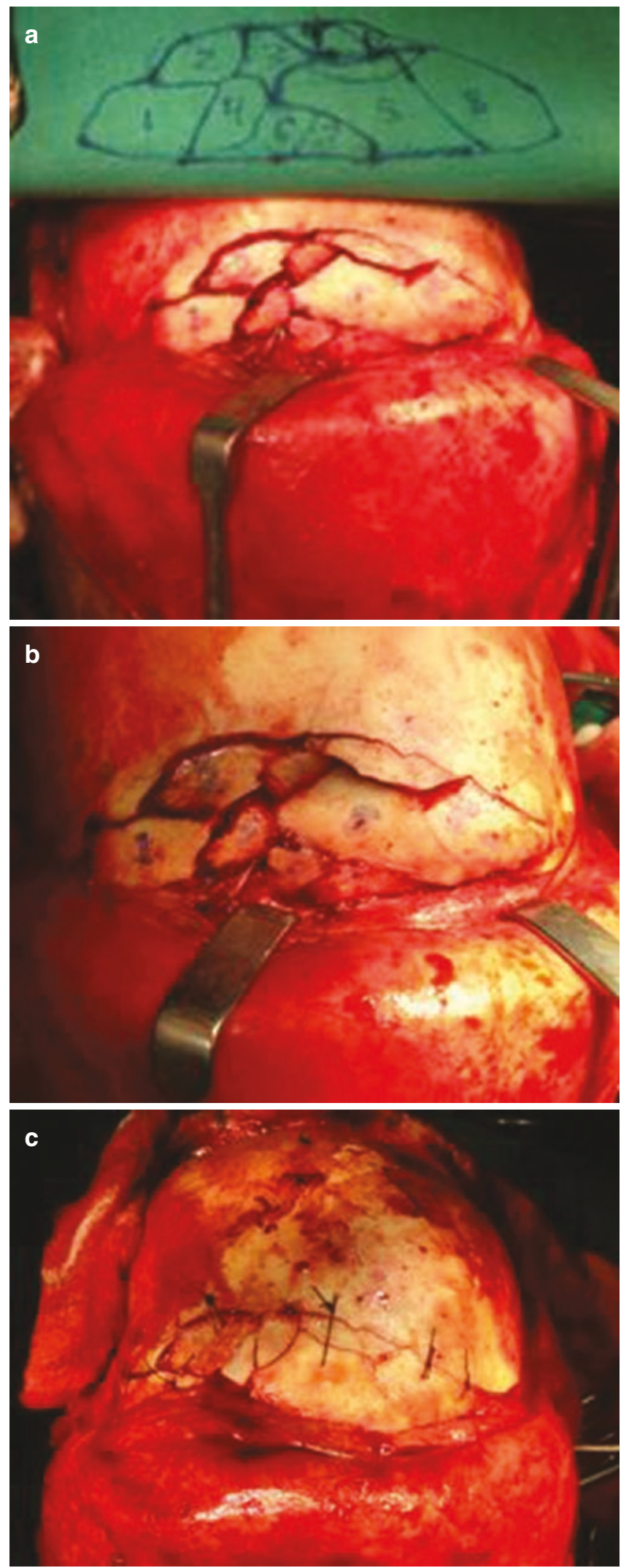

CAssociation of Oral and Maxillofacial Surgeons of India

Fig. 58.22 (a-c) Bone mapping/sketching in management of anterior table frontal sinus fracture
Box 58.7 Complications of Frontal Sinus Fractures [46]

\begin{tabular}{|c|c|}
\hline Immediate complications & Late complications \\
\hline 1. Wound infection & 1. Mucocele \\
\hline 2. CSF leak & 2. Mucopyocele \\
\hline 3. Paresthesia of supraorbital nerve & 3. Late frontal sinusitis \\
\hline 4. Frontal sinusitis & 4. Brain abscess \\
\hline 5. Meningitis & 5. Osteomyelitis of \\
\hline $\begin{array}{l}\text { 6. Neurological injuries secondary } \\
\text { to penetrating trauma or } \\
\text { displacement of frontal bone into } \\
\text { neurocranium }\end{array}$ & frontal bone \\
\hline
\end{tabular}

\subsubsection{Material Used for Sinus Obliteration} [43]

1. Hydroxyapatite

2. Glass wool

3. Bone

4. Cartilage

5. Muscle

6. Absorbable gelatin sponge

7. Temporalis fascia

8. Oxidized segmented cellulose

9. Acrylic or methyl methacrylate

10. Fat (commonly used)

\subsubsection{Cranialization $[44,45]$}

It is another technique to minimize the dead space in sinus. It involves removing posterior table thus permitting brain to expand into frontal sinus resulting in confluence between sinus cavity and anterior cranial fossa. It is done in cases with CSF leak and neurological injury due to displaced posterior table fracture. To isolate the splanchnocranium from the frontal sinus, a pericranial flap is used.

\subsubsection{Key Points}

- Actual or suspected fractures involving the frontonasal duct are an indication to remove the outer table, so the duct can be inspected.

- If outer table is comminuted and a bony segment over $1.5 \mathrm{~cm}$ in missing, a bone graft should be harvested to restore the outer table contour.

- The most common treatment for outer table fracture with injury to duct without inner table fracture is obliteration of frontal sinus to seal the frontonasal duct to prevent nasal infection.

- Adipose tissue from abdomen is used to fill the dead space of frontal sinus because of its resistance to infec- 
tion, slow resorption rate, and it is gradually replaced by the fibrous tissue.

Complications of frontal sinus fractures is given in Box 58.7.

\subsection{Conclusion}

The management of NOE and frontal sinus fracture is always a challenging task. The proper handling of MCL and nasofrontal duct is mandatory to get good post-operative results. Proper treatment planning in the form of incision selection, method of fixation and use of bone graft should be done to avoid unaesthetic results.

\section{References}

1. Milad Etemadi SH, Shahnaseri S, Soltani P, Motamedi MRK. Management of naso-orbito-ethmoid fractures: a 10-year review. Trauma Mon. 2017;22:292-30.

2. Brasileiro BF, Passeri LA. Epidemiological analysis of maxillofacial fractures in Brazil: a 5-year prospective study. Oral Surg Oral Med Oral Pathol Oral Radiol Endod. 2006;102(1):28-34.

3. Rosenberger E, Kriet JD, Humphrey C. Management of nasoethmoid fractures. Curr Opin Otolaryngol Head Neck Surg. 2013;21:410-6. (Anatomy of MCL, physical examination of the complex and displacement)

4. Poh E, Kakizaki H, Selva D, Leibovitch I. Anatomy of medial canthal tendon in Caucasians. Clin Exp Ophthalmol. 2012;40:170-3.

5. Merkx MA, Freihofer HP, Borstlap WA, van't Hoff MA. Effectiveness of primary correction of traumatic telecanthus. Int J Oral Maxillofac Surg. 1995;24:344-7.

6. Heine D, Catone GA, Bavitz B, Grenadier MR. Naso-orbitalethmoid injury: report of a case and review of the literature. Oral Surg Oral Med Oral Path. 2005;69(5):542-9.

7. Rowe NL. Rowe and Williams' maxillofacial injuries, vol. 2. 2nd ed. Edinburgh: Churchill Livinstone; 1994.

8. Markowitz BL, Manson PN, Sargent L, et al. Management of the medial canthal tendon in nasoethmoid orbital fractures: the importance of the central fragment in classification and treatment. Plast Reconstr Surg. 1991;87:843-853.

9. Burstein F, Cohen S, Hudgins R, Boydston W. Frontal basilar trauma: classification and treatment. Plast Reconstr Surg. 1997;99(5):1314-21.

10. Balaraman K, Ramani V, Bharathi R, Venkataramani H, Sabapathy SR. Outcome assessment of Nasoethmoid fractures. Int J Oral Maxillofac Surg. 2013;42(10):1220.

11. Ellis E III. Sequencing treatment for naso-orbito-ethmoid fractures. J Oral Maxillofac Surg. 1993;51:543-558.

12. Nguyen M, Koshy JC, Hollier LH Jr. Pearls of nasoorbitoethmoid trauma management. Semin Plast Surg. 2010;24:383-8.

13. Dingman RO, Grabb WC, Oneal RM. Management of injuries of the naso-orbital complex. Arch Surg. 1969;98:566-71.

14. Mustarde JC. Epicanthus and telecanthus. Int Opthalmol Clin. 1964;4:359.

15. Cruse C, Blevins PK, Luce EA. Naso-ethmoid-orbital fractures. J Trauma. 1980;20:551.
16. Gruss JS. Naso-ethmoid-orbital fractures: classification and role of primary bone grafting. Plast Reconstr Surg. 1985;75:303.

17. Baliga S, Urolagin SB. Transnasal fixation of NOE fracture: minimally invasive approach. J Maxillofac Oral Surg. 2012;11(1):34-7.

18. Timoney PJ, Sokol JA, Hauck MJ, Lee HB, Nunery WR. Transcutaneous medial canthal tendon incision to the medial orbit. Ophthal Plast Reconstr Surg. 2012;28:140-4.

19. Goldenberg DC, Bastos EO, Alonso N, Friedhofer H, Ferreira MC. The role of micro-anchor devices in medial canthopexy. Ann Plast Surg. 2008;61:47-51.

20. Pawar SS, Rhee JS. Frontal sinus and naso-orbital-ethmoid fractures. JAMA Facial Plast Surg. 2014;16:284-9.

21. Herford AS, Ying T, Brown B. Outcomes of severely comminuted (type III) nasoorbitoethmoid fractures. J Oral Maxillofac Surg. 2005;63:1266-77.

22. Potter JK, Muzaffar AR, Ellis E, Rohrich RJ, Hackney FL. Aesthetic management of the nasal component of naso-orbital ethmoid fractures. Plast Reconstr Surg. 2006;117(1):10e-8e.

23. Vora NM, Fedok FG. Management of the central nasal support complex in naso-orbital ethmoid fractures. Facial Plast Surg. 2000;16(2):181-91.

24. Becelli R, Renzi G, Mannino G, Cerulli G, Iannetti G. Posttraumatic obstruction of lacrimal pathways: a retrospective analysis of 58 consecutive naso-orbitoethmoid fractures. J Craniofac Surg. 2004;15:29-33

25. Wei J-J, Tang Z-L, Liu L, Liao X-J, Yu Y-B, Jing W. The management of naso-orbital-ethmoid (NOE) fractures. Chinese $\mathrm{J}$ Traumatol. 2015;18:296-301.

26. Bell RB, Dierks EJ, Homer L, Potter BE. Management of cerebrospinal fluid leak associated with craniomaxillofacial trauma. J Oral Maxillofac Surg. 2004;62:676-84.

27. Gerbino G, Roccia F, Benech A, Caldarelli C. Analysis of 158 frontal sinus fractures: current surgical management and complications. J Craniomaxillofac Surg. 2000;28:133-139.

28. Haug RH, Cunningham LL. Management of fractures of the frontal bone and frontal sinus, selected Readings. Oral and Maxillofacial Surgery. 2002;10(6):1-32.

29. Wallis A, Donald PJ. Frontal sinus fractures: a review of 72 cases. Laryngoscope. 1988;98:593.

30. Finkle DR, Ringler SL, Luttenton CR, Beernink JH, Peterson NT, Dean RE. Comparison of the diagnostic methods used in maxillofacial trauma. Plast Reconstr Surg. 1985;75(1):32-41.

31. Stanley RB Jr. Fractures of the frontal sinus. Clin Plast Surg. 1989;16(1):115-23.

32. Gonty AA, Marciani RD, Adornato DC. Management of frontal sinus fractures: a review of 33 cases. J Oral Maxillofac Surg. 1999;57:372-9.

33. Rohrich RJ, Hollier LH. Management of frontal sinus fractures. Changing concepts. Clin Plast Surg. 1992;19:219-32.

34. Khan M, Rai A, Jain A. A simple and effective scalp tourniquet for controlling scalp hemorrhage. J Maxillofac Oral Surg. 2018;17(2):264-5.

35. Manolidis S. Frontal sinus injuries: associated injuries and surgical management of 93 patients. J Oral Maxillofac Surg. 2004;62:882-91.

36. Fattahi T, Salman S. An aesthetic approach in the repair of anterior frontal sinus fractures. Int $\mathbf{J}$ Oral Maxillofac Surg. 2016;45(9):1104-7

37. Cole P, Kaufman Y, Momoh A, et al. Techniques in frontal sinus fracture repair. Plast Reconstr Surg. 2009;123(5):1578-9.

38. Weathers WM, Wolfswinkel EM, Hatef DA, Lee EI, Brown RH, Hollier LH Jr. Frontal sinus fractures: a conservative shift. Craniomaxillofac Trauma Reconstr. 2013;6(3):155-60. 
39. Rai A, et al. "Bone mapping/sketching" in management of anterior table frontal sinus fracture. J Maxillofac Oral Surg. 2017;16(1):127-30.

40. Yoo MH, et al. Endoscopic transnasal reduction of an anterior table frontal sinus fracture: technical note. Int Journal Oral Maxfac Surg. 2008;37:573-5.

41. Freeman JL, Winston KR. Breach of posterior wall of frontal sinus: management with preservation of the sinus. World Neurosurg. 2015;83(6):1080-9.

42. Rohrich RJ, Hollier L. The role of the nasofrontal duct in frontal sinus fracture management. J Craniomaxillofac Trauma. 1996;2:31-40.

43. Mickel TJ, Rohrich RJ, Robinson JB Jr. Frontal sinus obliteration: a comparison of fat, muscle, bone, and spontaneous osteo- neogenesis in the cat model. Plast Reconstr Surg. 1995;95(3): 586-92.

44. Scholsem M, Scholtes F, Collignon F, et al. Surgical management of anterior cranial base fractures with cerebrospinal fluid fistulae: a single institution experience. Neurosurgery. 2008;62: 463-71.

45. Pollock R, Hill J, Davenport D, et al. Cranialization in a cohort of 154 consecutive patients with frontal sinus fractures (1987-2007): review and update of a compel- ling procedure in the selected patient. Ann Plast Surg. 2013;71(1):54-9.

46. Guy WM, Brissett AE. Contemporary management of traumatic fractures of the frontal sinus. Otolaryngol Clin North Am. 2013;46(5):733-48.

Open Access This chapter is licensed under the terms of the Creative Commons Attribution 4.0 International License (http://creativecommons. org/licenses/by/4.0/), which permits use, sharing, adaptation, distribution and reproduction in any medium or format, as long as you give appropriate credit to the original author(s) and the source, provide a link to the Creative Commons license and indicate if changes were made.

The images or other third party material in this chapter are included in the chapter's Creative Commons license, unless indicated otherwise in a credit line to the material. If material is not included in the chapter's Creative Commons license and your intended use is not permitted by statutory regulation or exceeds the permitted use, you will need to obtain permission directly from the copyright holder. 